\title{
Evaluation of interference fit and bone damage of an uncemented femoral knee implant
}

Citation for published version (APA):

Berahmani, S., Hendriks, M., de Jong, J. J. A., van den Bergh, J. P. W., Maal, T., Janssen, D., \& Verdonschot, N. (2018). Evaluation of interference fit and bone damage of an uncemented femoral knee implant. Clinical Biomechanics, 51, 1-9. https://doi.org/10.1016/j.clinbiomech.2017.10.022

Document status and date:

Published: 01/01/2018

DOI:

10.1016/j.clinbiomech.2017.10.022

Document Version:

Publisher's PDF, also known as Version of record

Document license:

Taverne

Please check the document version of this publication:

- A submitted manuscript is the version of the article upon submission and before peer-review. There can be important differences between the submitted version and the official published version of record.

People interested in the research are advised to contact the author for the final version of the publication, or visit the DOI to the publisher's website.

- The final author version and the galley proof are versions of the publication after peer review.

- The final published version features the final layout of the paper including the volume, issue and page numbers.

Link to publication

\footnotetext{
General rights rights.

- You may freely distribute the URL identifying the publication in the public portal. please follow below link for the End User Agreement:

www.umlib.nl/taverne-license

Take down policy

If you believe that this document breaches copyright please contact us at:

repository@maastrichtuniversity.nl

providing details and we will investigate your claim.
}

Copyright and moral rights for the publications made accessible in the public portal are retained by the authors and/or other copyright owners and it is a condition of accessing publications that users recognise and abide by the legal requirements associated with these

- Users may download and print one copy of any publication from the public portal for the purpose of private study or research.

- You may not further distribute the material or use it for any profit-making activity or commercial gain

If the publication is distributed under the terms of Article $25 \mathrm{fa}$ of the Dutch Copyright Act, indicated by the "Taverne" license above, 


\title{
Evaluation of interference fit and bone damage of an uncemented femoral knee implant
}

\author{
Sanaz Berahmani ${ }^{\mathrm{a}, *}$, Maartje Hendriks ${ }^{\mathrm{a}}$, Joost J.A. de Jong ${ }^{\mathrm{b}, \mathrm{c}}$, Joop P.W. van den Bergh ${ }^{\mathrm{b}, \mathrm{d}, \mathrm{d}, \mathrm{e}}$, \\ Thomas Maal ${ }^{\mathrm{f}}$, Dennis Janssen ${ }^{\mathrm{a}}$, Nico Verdonschot ${ }^{\mathrm{a}, \mathrm{g}}$ \\ ${ }^{a}$ Radboud university medical center, Radboud Institute for Health Sciences, Orthopaedic Research Lab, P.O. Box 9101, 6500 HB Nijmegen, The Netherlands \\ ${ }^{\mathrm{b}}$ NUTRIM School for Nutrition and Translational Research in Metabolism, Maastricht University Medical Center, Maastricht, The Netherlands \\ ${ }^{\mathrm{c}}$ Department of Rheumatology, Maastricht University Medical Center, Maastricht, The Netherlands \\ ${ }^{\mathrm{d}}$ Department of Internal Medicine, VieCuri Medical Center, Venlo, The Netherlands \\ ${ }^{\mathrm{e}}$ Faculty of Medicine and Life Sciences, Hasselt University, Hasselt, Belgium \\ ${ }^{\mathrm{f}}$ Radboud university medical center, Department of Oral and Maxillofacial Surgery, Nijmegen, The Netherlands \\ ${ }^{\mathrm{g}}$ Laboratory for Biomechanical Engineering, University of Twente, Enschede, The Netherlands
}

\section{A R T I C L E I N F O}

\section{Keywords:}

Uncemented total knee replacement

Bone damage

Micro-CT scan

Bone density

Press-fit interference fit

\begin{abstract}
A B S T R A C T
Background: During implantation of an uncemented femoral knee implant, press-fit interference fit provides the primary stability. It is assumed that during implantation a combination of elastic and plastic deformation and abrasion of the bone will occur, but little is known about what happens at the bone-implant interface and how much press-fit interference fit is eventually achieved.

Methods: Five cadaveric femora were prepared and implantation was performed by an experienced surgeon. Micro-CT- and conventional CT-scans were obtained pre- and post-implantation for geometrical measurements and to measure bone mineral density. Additionally, the position of the implant with respect to the bone was determined by optical scanning of the reconstructions. By measuring the differences in surface geometry, assessments were made of the cutting error, the actual interference fit, the amount of bone damage, and the effective interference fit.

Findings: Our analysis showed an average cutting error of $0.67 \mathrm{~mm}$ (SD $0.17 \mathrm{~mm}$ ), which pointed mostly towards bone under-resections. We found an average actual AP interference fit of $1.48 \mathrm{~mm}$ (SD $0.27 \mathrm{~mm}$ ), which was close to the nominal value of $1.5 \mathrm{~mm}$.

Interpretation: We observed combinations of bone damage and elastic deformation in all bone specimens, which showed a trend to be related with bone density. Higher bone density tended to lead to lower bone damage and higher elastic deformation. The results of the current study indicate different factors that interact while implanting an uncemented femoral knee component. This knowledge can be used to fine-tune design criteria of femoral components to achieve adequate primary stability for all patients.
\end{abstract}

\section{Introduction}

The primary fixation of an uncemented femoral total knee replacement (TKR) component is achieved by a press-fit placement of the implant. The objective is to restrict micromotions at the bone-implant interface, which is a prerequisite for successful bone-ingrowth and stable biological fixation on the long term (Kienapfel et al., 1999; Jasty et al., 1997; Pilliar et al., 1986). The press-fit fixation is obtained due to the fact that the inside dimensions of the implant are slightly undersized with respect to the bone cuts created intra-operatively. This relative difference in dimensions is commonly known as the interference fit.

The actual interference fit is often different from the nominal interference fit, as it depends on the final implant position (which does not necessarily line up with the pre-planned position), and on the accuracy of the prepared bone cuts. In addition, during the implantation process compressive stresses are being built up inside the bone and at the implant-bone interface. The combination of the compressive stresses, the shearing motion at the implant-bone interface and the rough implant surface will cause plastic deformation and abrasion of the bone, effectively altering the actual interference fit (Bishop et al., 2014). However, still a considerable amount of elastic energy is stored in the bone,

\footnotetext{
* Corresponding author at: Orthopaedic Research Lab, Radboud University Medical Center, P.O. Box 9101, 6500 HB Nijmegen, The Netherlands.

E-mail address: sanaz.berahmani@radboudumc.nl (S. Berahmani).
} 
responsible for the final effective interference fit and subsequent stability of the implant (Damm et al., 2015).

The amount of interference fit designed in the implant system can be influenced by careful tuning of the intrinsic accuracy of the instruments that are used to prepare the bone cuts (Hungerford, 1991) and position the implant (Lennox et al., 1988; Hadi et al., 2015), which in turn may allow for compensation of inalterable patient-related factors, such as low bone density to optimize stability (Aro et al., 2012; Berahmani et al., 2015). Surprisingly little is known about the actual and effective interference fit, or on how much bone damage actually occurs during implantation of the femoral component. Therefore, interference fit is usually ignored or simplified when computational models based on finite element analysis (FEA) are implemented to preclinically test implants (Berahmani et al., 2016; Abdul-Kadir et al., 2008; Taylor et al., 2012), limiting the FEA capability to entirely evaluate new implant designs. Therefore, the main goal of the current study was to assess the actual and effective interference fit and amount of bone damage occurring during implantation of an uncemented femoral knee component. For this purpose, several optical and imaging techniques were used to measure geometrical changes occurring to the bone during the procedure.

\section{Methods}

In short, components were implanted on cadaver femurs, while before, during, and after implantation a series of scans were made that allowed for monitoring the changes that took place in the underlying bone. In the following sections, the materials and methods used for these analyses will be described, as well as all the sequential steps that were taken.

\subsection{Implants}

The cementless Sigma ${ }^{\circledR}$ PFC cruciate retaining femoral knee implant (DePuy Synthes Joint Reconstruction, Leeds, UK) was used. This implant has a porous surface coating, Porocoat ${ }^{\circledR}$ (DePuy Synthes Joint Reconstruction, Warsaw, IN, USA), which is comprised of randomly arranged spherical beads. The implant system has a nominal interference fit of $0.75 \mathrm{~mm}$ at the anterior, distal, and posterior cut planes, which is equal to the average thickness of surface coating.

\subsubsection{Assessment of implant deformation}

To capture the deformation of the implant during implantation, four strain gauges were connected to the outer surface of each implant medially and laterally, in the anterior and posterior region (Fig. 1A). Strain gauges were placed at locations nearest to where peak strains were expected to occur (based on previous Finite Element (FE) analyses
(Berahmani et al., 2016)). Extra care was taken not to position them at locations where the implantation instruments contacted the implant. Strain was recorded using QuickDAQ (Data Translation GmbH, Germany) at $100 \mathrm{~Hz}$, a few seconds before implantation until $10 \mathrm{~s}$ after implantation. The average strain of the last $10 \mathrm{~s}$ was used for the analyses.

\subsection{Bone specimens and implantation procedure}

Two pairs and one single fresh-frozen cadaveric femora (85 years old (SD 3); 1 pair was male) were selected from ten donated femurs to exclude highly osteoporotic bones by assessing X-ray images (provided by the Anatomy Department of the Radboud university medical center). The bone specimens were thawed at room temperature and an experienced orthopaedic surgeon made the bone cuts following the normal surgical procedure using standard intra-medullar instrumentation. A femoral cutting block was fixed with two threaded pins to first resect about $9 \mathrm{~mm}$ of distal femur from the most prominent distal part of condyle, followed by determination of the required implant size, which resulted in four size 5 implants and one size 3 . All cuts were made using an oscillating saw with a blade thickness of $1.47 \mathrm{~mm}$ (DePuy Synthes, Leeds, UK) and two holes were drilled for the femoral pegs. The implants were subsequently placed by the same surgeon.

\subsection{Scanning procedures}

\subsubsection{CT-scanning}

To evaluate the bone mineral density (BMD), after the cutting session (but before implantation), the bone specimens were 3D-scanned using computed tomography (CT) with in-plane resolution of $0.351 \mathrm{~mm}$ and slice thickness of $0.6 \mathrm{~mm}(530 \mathrm{~mA} ; 120 \mathrm{Kv}$; Siemens Somatom Sensation 64, Siemens AG, Germany). To convert the Hounsfield Units to BMD, a hydroxyapatite calibration phantom (solid, 0, 50, 100, $200 \mathrm{mg} / \mathrm{ml}$ calcium hydroxyapatite, Image Analysis, Columbia, KY) was scanned along with the cadavers. BMD was measured in three volumes of interest based on the dimension of the implant in the anterior region (ANT) (implant size 3: $18 \times 35 \times 5 \mathrm{~mm}$ and implant size 5: $20 \times 40 \times 5 \mathrm{~mm}$ (height $\times$ width $\times$ depth) and posterior condyles (lateral (PL) and medial (PM)) (size 3: $18 \times 24 \times 5 \mathrm{~mm}$ and size 5: $20 \times 27 \times 5 \mathrm{~mm}$ ) using a previously protocolized technique (Berahmani et al., 2015). The anterior and posterior regions were selected due to their main role in providing initial fixation in the anteroposterior (AP) direction.

\subsubsection{Micro-CT scanning}

To capture the bone damage occurring during implantation as accurately as possible, after the cutting session, micro-CT scans of the
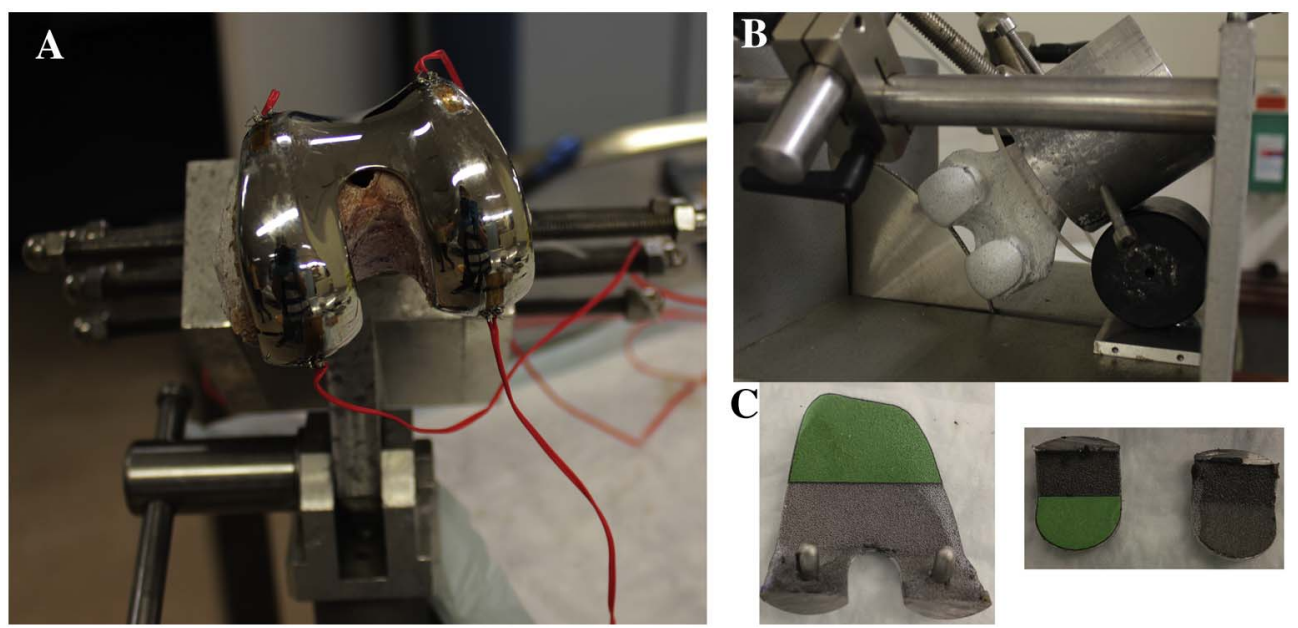

Fig. 1. A) Four strain gauges were connected to each implant to record implant's deformation. B) Implants were sawed using a diamond blade to access bone surface. $C$ ) The regions of interest are demonstrated (green area) in the anterior flange and posterior condyles (ROI is only shown in one condyle). (For interpretation of the references to colour in this figure legend, the reader is referred to the web version of this article.) 
resected bone specimens were made (XtremeCT II, SCANCO Medical AG, Bruettisellen, Switzerland; peak voltage of $68 \mathrm{kVp}$, tube current of $1470 \mu \mathrm{A}, 200 \mathrm{~ms}$ integration time). All images were reconstructed using an isotropic voxel size of $60.7 \mu \mathrm{m}$. These scans served as the baseline for the damage assessment. Next, the femoral components were placed on the femurs as described earlier. After implantation and performing a series of measurements on the specimens, the implants were split through the condyles using an electric diamond-blade cutting machine, which allowed us to gently remove the components without causing additional bone damage (Fig. 1B). Subsequently, the micro-CT scans of the distal femurs were repeated, to evaluate the amount of damage. Using the micro-CT data sets, surface meshes of the outer surface of the bone specimens (pre- and post-implantation) were created using medical imaging software (Mimics 14 and 18 \& 3-matic ${ }^{\circledR}$, Materialise, Leuven, Belgium) for further analyses. Due to the high resolution of the micro-CT scan, which resulted in a great number of slides, the segmentation required multiple steps. In the first step, the bone layer was separated from air based on a Hounsfield Unit (HU) threshold. To fill in the gaps between the bone voxels, several morphology operations were applied to create a completely solid layer of bone, including closed connectivity and Boolean operations. Afterwards, matrix reduction and smoothing were used to create a regular 3D surface mesh with an acceptable size. The quality of surface mesh was verified in 3 -Matic ${ }^{\circledR}$ to achieve a high-quality surface mesh.

\subsubsection{Optical scanning}

To determine the relative position of the implant with respect to the bone, after implantation (Fig. 2A), optical scans were made of the reconstructed distal femurs (TRIOS Color-P13, 3Shape, Copenhagen, Denmark) (Fig. 2B). The accuracy of the system as provided by the manufacturer was $100 \mu \mathrm{m}$.

\subsection{Outcome parameters}

\subsubsection{Cutting error}

The nominal cutting planes were provided by the manufacturer, which were used to assess cutting errors. For this purpose, the nominal distal cutting planes were superimposed onto the distal face of preimplantation bone. As during surgery the distal cut is the first cutting plane, this surface was taken as the reference plane. Since the main press-fit is provided in the AP direction, deviations in the anterior and posterior regions were of main interest. Therefore, three regions of interest (ROIs) corresponding to the shape of anterior flange and posterior condyles were defined on the bone surface: anterior (ANT), the medial (PM) and lateral (PL) posterior condyle (Fig. 1C). Using a Matlab script (Matlab 7.12.0 (R2011a), Mathworks, MA, USA), the AP distance between each point from the cutting planes and the bony surfaces was calculated per ROI by finding two closest points from two surfaces and then extracting the AP distance between them. In this way, the maximum and average AP distance was obtained per ROI.

\subsubsection{Actual interference fit}

To evaluate the actual interference fit, CAD files of the implants
Table 1

Bone mineral density (BMD) for the three volumes of interest (VOI) is given. In addition, average BMD per specimen is also stated.

\begin{tabular}{|c|c|c|c|c|}
\hline \multirow{2}{*}{$\begin{array}{l}\text { Specimen (side (age, } \\
\text { sex, and implant size) }\end{array}$} & \multicolumn{4}{|c|}{ BMD per VOI $\left(\mathrm{mg} / \mathrm{cm}^{3}\right)$} \\
\hline & Anterior & $\begin{array}{l}\text { Posterior- } \\
\text { medial }\end{array}$ & $\begin{array}{l}\text { Posterior- } \\
\text { lateral }\end{array}$ & Average (SD) \\
\hline $\begin{array}{l}\text { Specimen 1-Left (83, } \\
\quad \text { F, 3) }\end{array}$ & 170.84 & 176.2 & 221.79 & $\begin{array}{l}189.61 \\
(8.00)\end{array}$ \\
\hline $\begin{array}{l}\text { Specimen 2-Left (89, } \\
\quad \text { F, 5) }\end{array}$ & 121.44 & 96.8 & 143.1 & $\begin{array}{l}120.45 \\
(23.17)\end{array}$ \\
\hline $\begin{array}{l}\text { Specimen 2-Right (89, } \\
\quad \text { F, 5) }\end{array}$ & 139.33 & 100.62 & 184.14 & $\begin{array}{l}141.36 \\
(41.80)\end{array}$ \\
\hline $\begin{array}{l}\text { Specimen 3-Left (82, } \\
\qquad \mathrm{M}, 5)\end{array}$ & 256.83 & 233.94 & 314.27 & $\begin{array}{l}268.35 \\
(41.38)\end{array}$ \\
\hline $\begin{array}{l}\text { Specimen 3-Right (82, } \\
\quad \text { M, 5) }\end{array}$ & 285.08 & 284.89 & 384.65 & $\begin{array}{l}318.21 \\
(57.54)\end{array}$ \\
\hline
\end{tabular}

were provided by the manufacturer. Using an iterative closest point (ICP) algorithm, the surface mesh of the implant (based on the CAD file) and bone (based on the pre-implantation micro-CT) were superimposed on the optical scan of each reconstruction (Fig. 2C). The average AP distance between the surface of the pre-implantation femur and the internal surface of implant was determined for the defined ROIs. This measure was taken as the actual interference fit after implantation.

\subsubsection{Bone damage - outer surface}

To evaluate the amount of damage caused during the implantation process, the surface meshes of the pre- and post-implantation micro-CT scans were registered on top of each other using the ICP algorithm. Again, the average AP distance between the surface of the pre- and postimplantation femurs was determined for the defined ROIs.

\subsubsection{Bone damage - internal}

In addition to the surface analyses, visual inspection of the actual pre- and post-implantation micro-CT scans was performed to evaluate the bone damage at the micro-level. For this purpose, the micro-CT scans were visually assessed to investigate changes in trabecular structure, abrasion, and possible micro-fractures. Since during the repetitive bone scans the specimens were not placed in the exact same orientation, micro-CT slices from the same distance from the most distal slice were selected and compared.

\subsubsection{Effective interference fit}

To measure the elastic deformation of the bone which is basically a reflection of the effective interference fit, the AP distance between the surface mesh of post-implantation scan and the correspondent node from internal surface of implant was obtained.

\subsection{Data analysis}

Outcome parameters (cutting error, actual interference fit, effective interference fit, and bone damage) per ROI were demonstrated in two manners: a frequency plot with a surface fraction on the vertical axis,
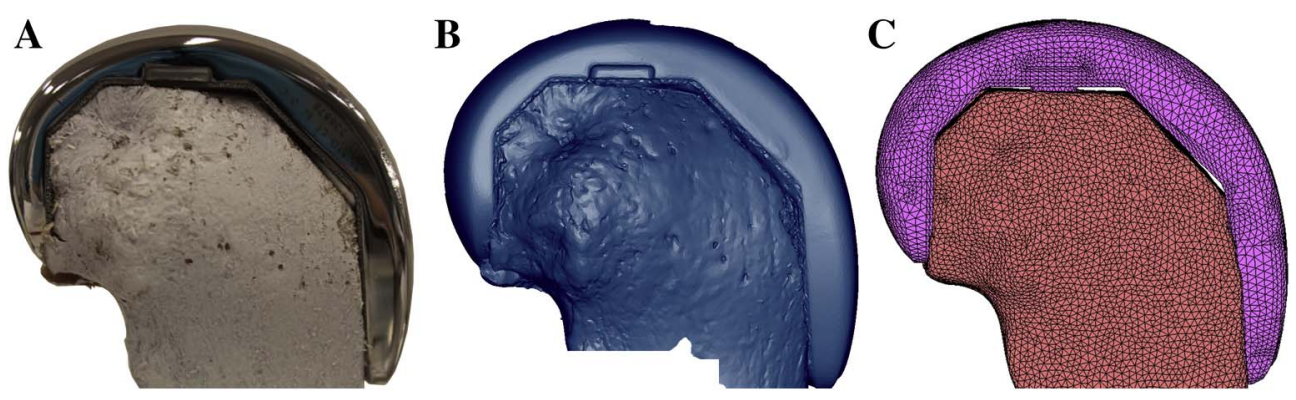

Fig. 2. A) After implantation, an optical scan of bone and implant was made (B), which was utilized to determine the position of the implant with respect to the bone (C). 
A Pre-implantation micro-CT vs. nominal cut planes
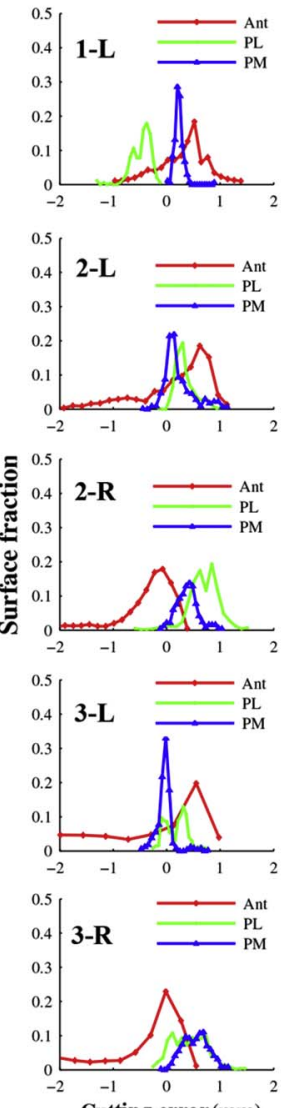

Cutting error $(\mathbf{m m})$
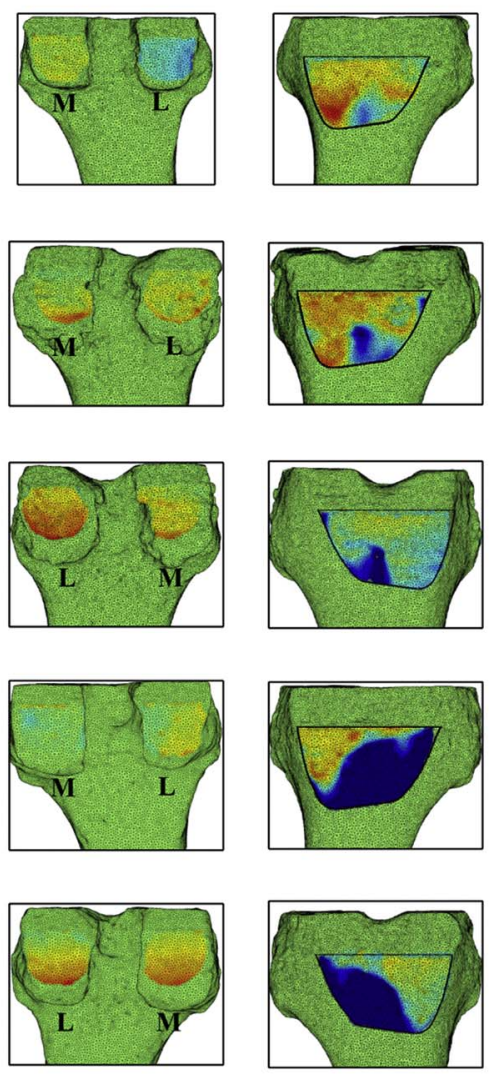

Posterior

Anterior
B

Pre-implantation micro-CT vs. Implant's surface
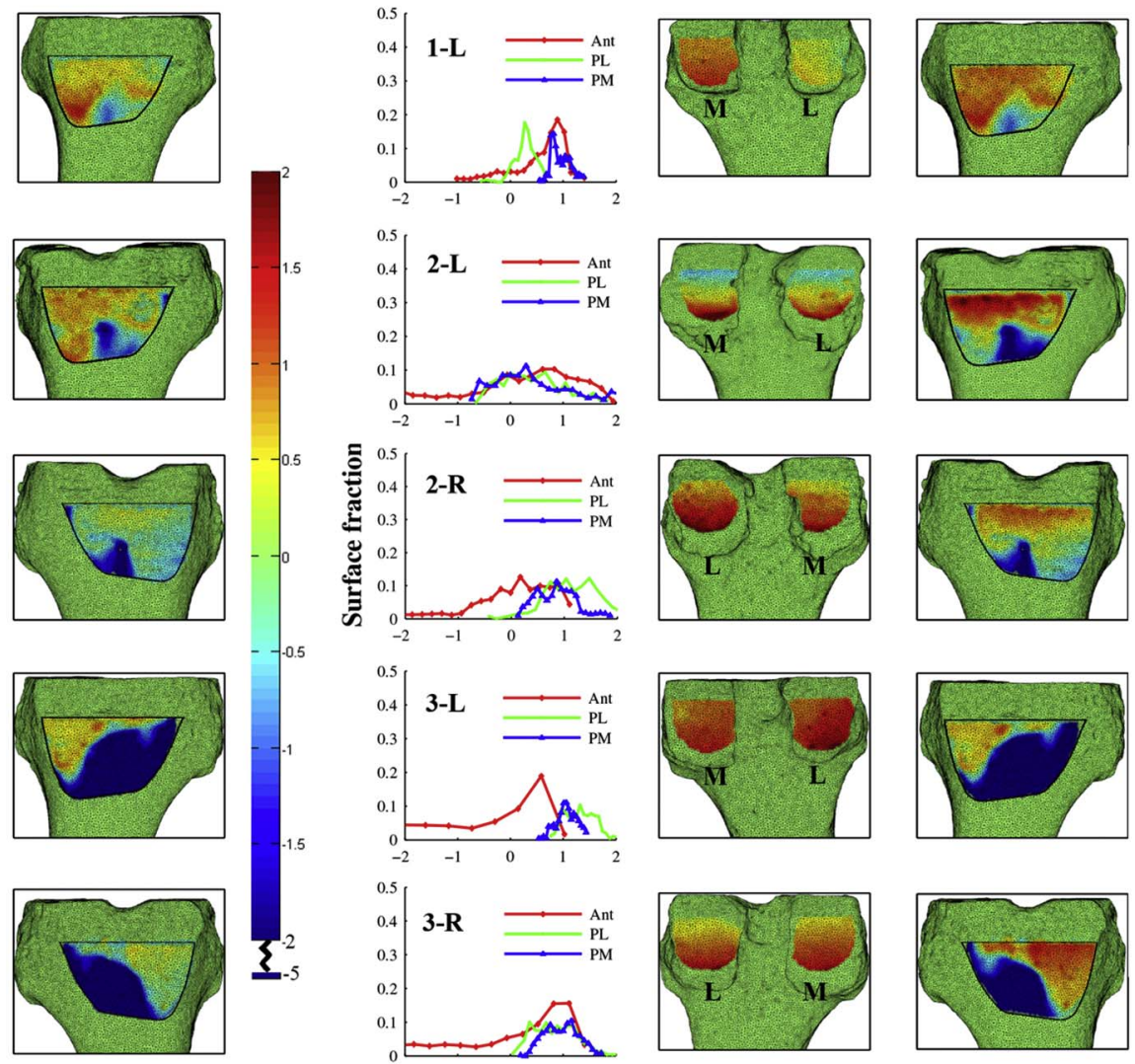

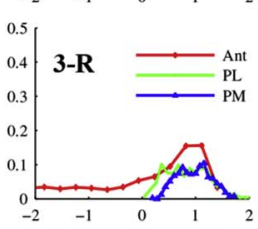

Actual interference (mm)

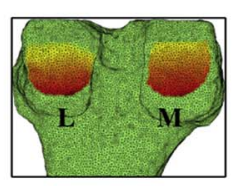

Posterior

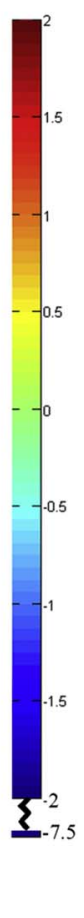

Anterior

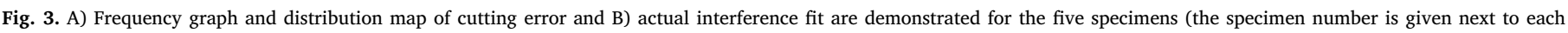

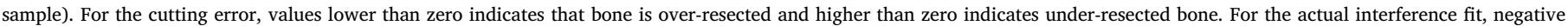

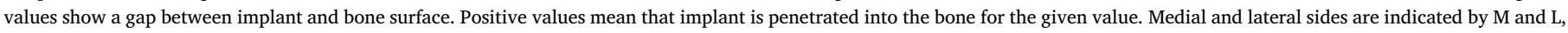
respectively.

A

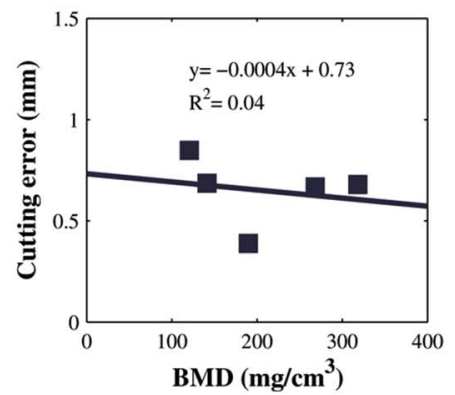

B

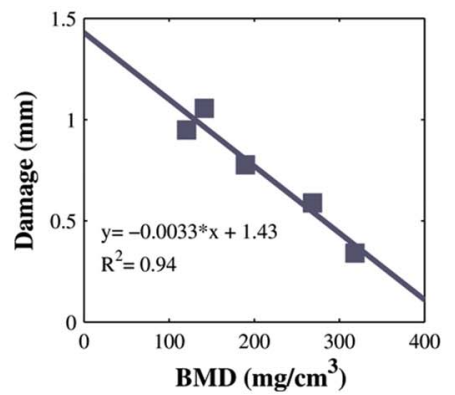

C

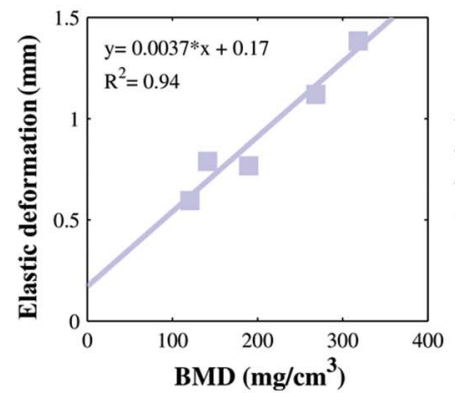

D

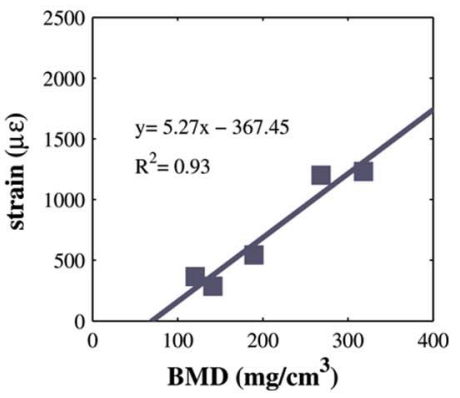

Fig. 4. A) The relationships between BMD with cutting error, B) damage, C) effective interference fit, and D) strain gauge measurement are demonstrated.

and a distribution map on the surface mesh of the pre-implantation micro-CT. It should be noted that the areas with prosthetic overhang in the flange area was excluded in the calculation of the average values in the anterior ROI. In addition, the average of each of the outcome parameters in the AP direction was obtained by first averaging the average of the posterior regions and then summed it with the average of anterior region; hence, these values represent each sample instead of each ROI. Linear regression analysis was used to evaluate the correlation between each outcome parameter and BMD.

\section{Results}

\subsection{Bone density}

The BMD in the three volumes of interest are given with the average value in Table.1. The distribution of BMD showed a wide range from low to high bone density. The bones within the two pairs had similar values.

\subsection{Cutting error}

None of the specimens had a perfect resection, with a tendency towards more under- than over-resected bone, which occurred 

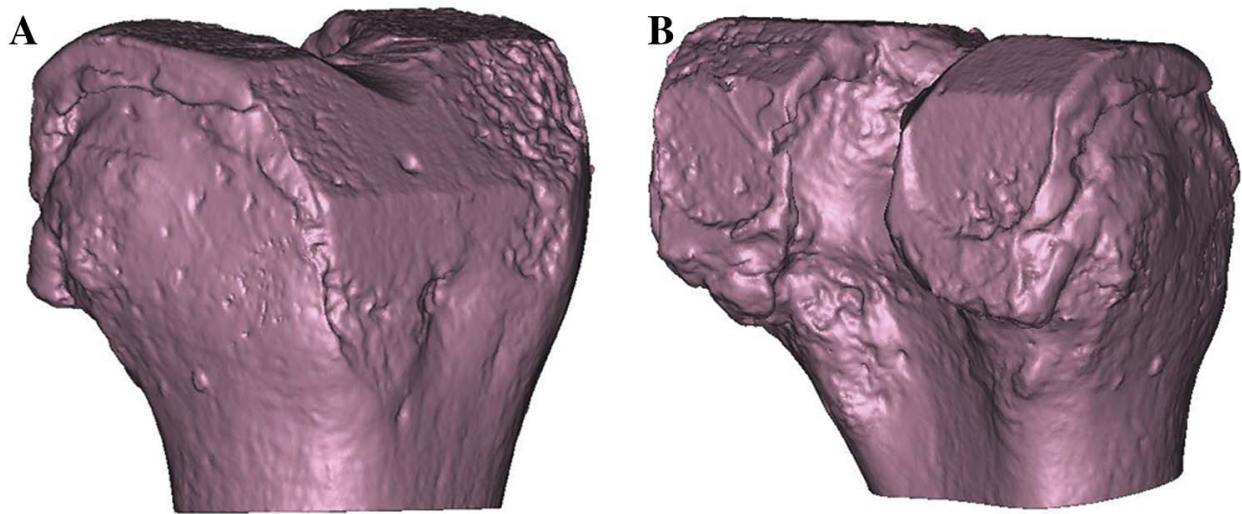

Fig. 5. A) A typical surface mesh of post-implantation micro-CT (specimen 2-L) next to the real specimen is shown. It can be seen that anterior flange was smooth (A) while posterior condyles had crushed surface (B).

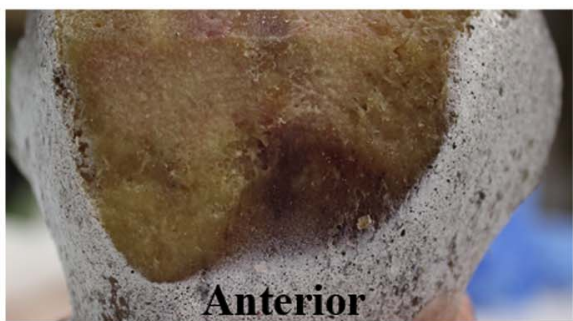

A
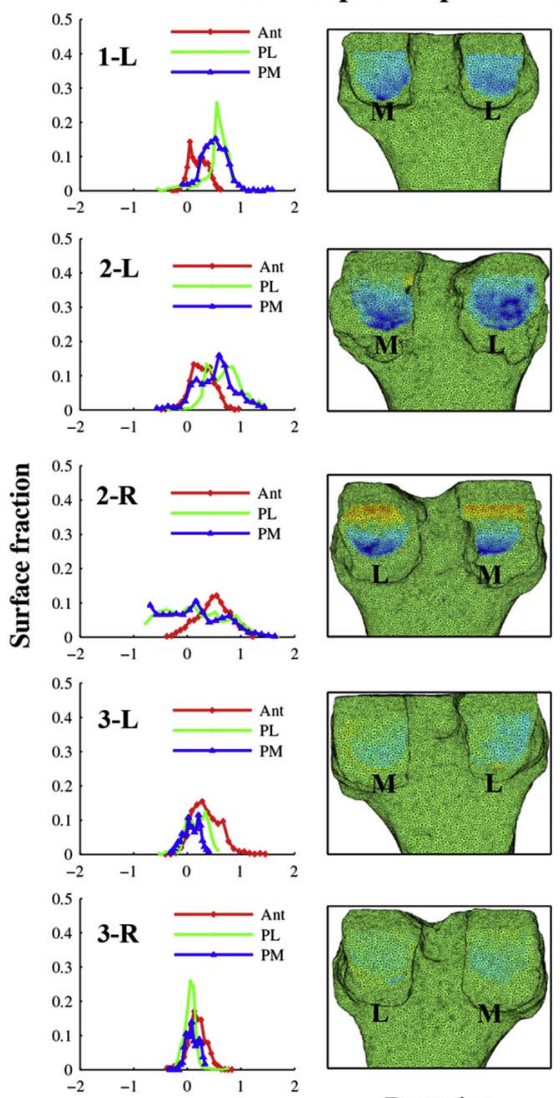

Damage (plastic deformation+ abrasion)(mm) Posterior

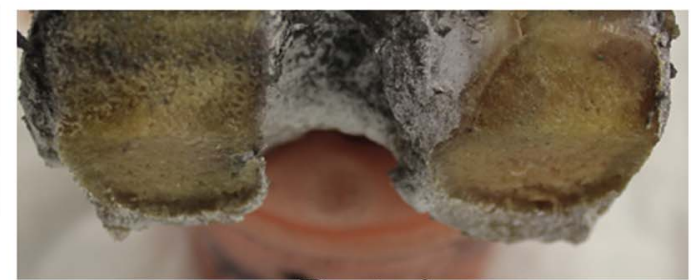

Posterior
B
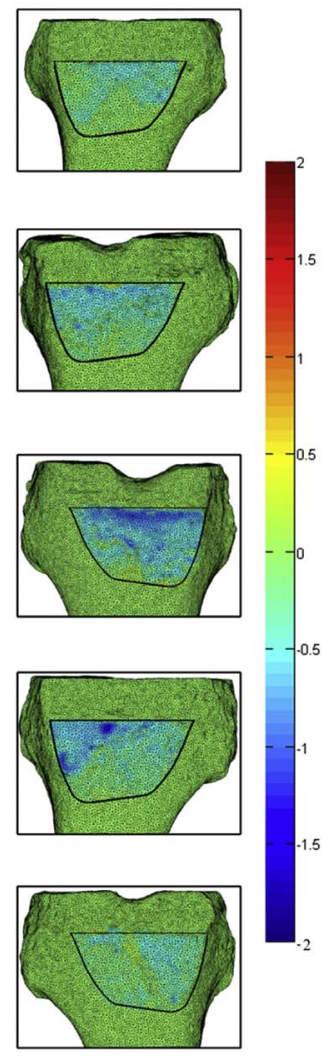

Anterior
Post-implantation micro-CT vs. Implant's surface
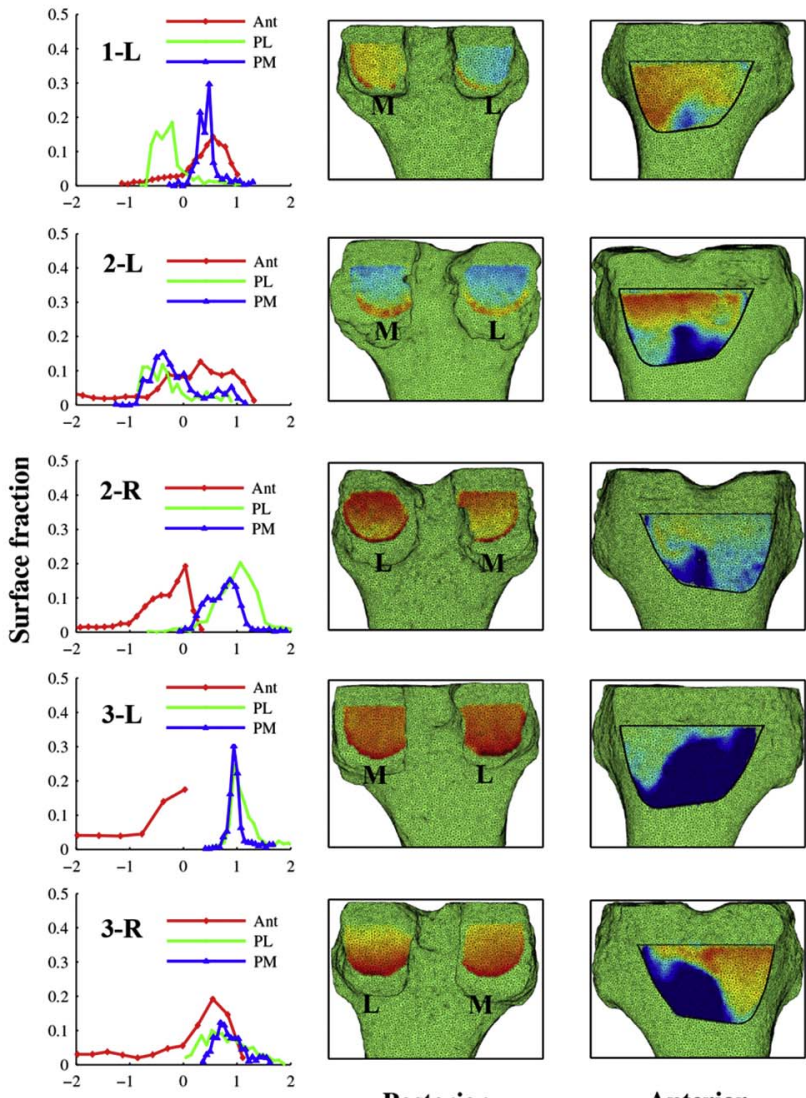

Posterior

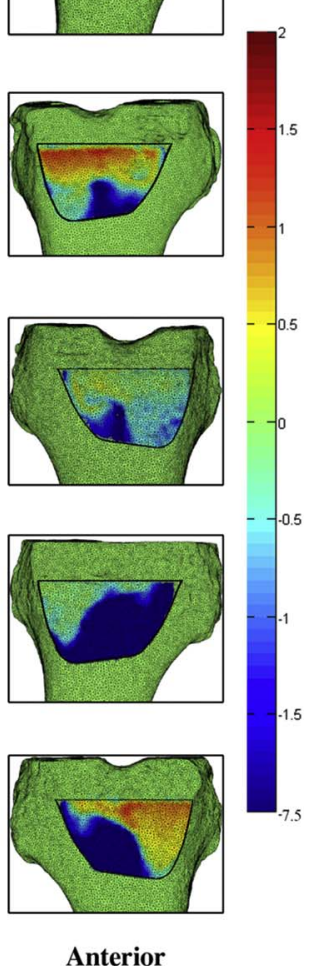

Anterior

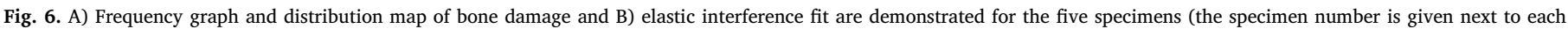

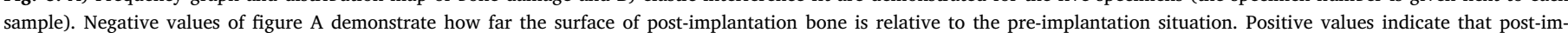

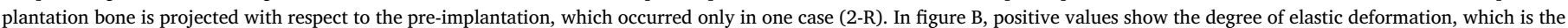
distance between surface mesh of post-implantation bone and implant surface. Medial and lateral sides are indicated by M and L, respectively. 


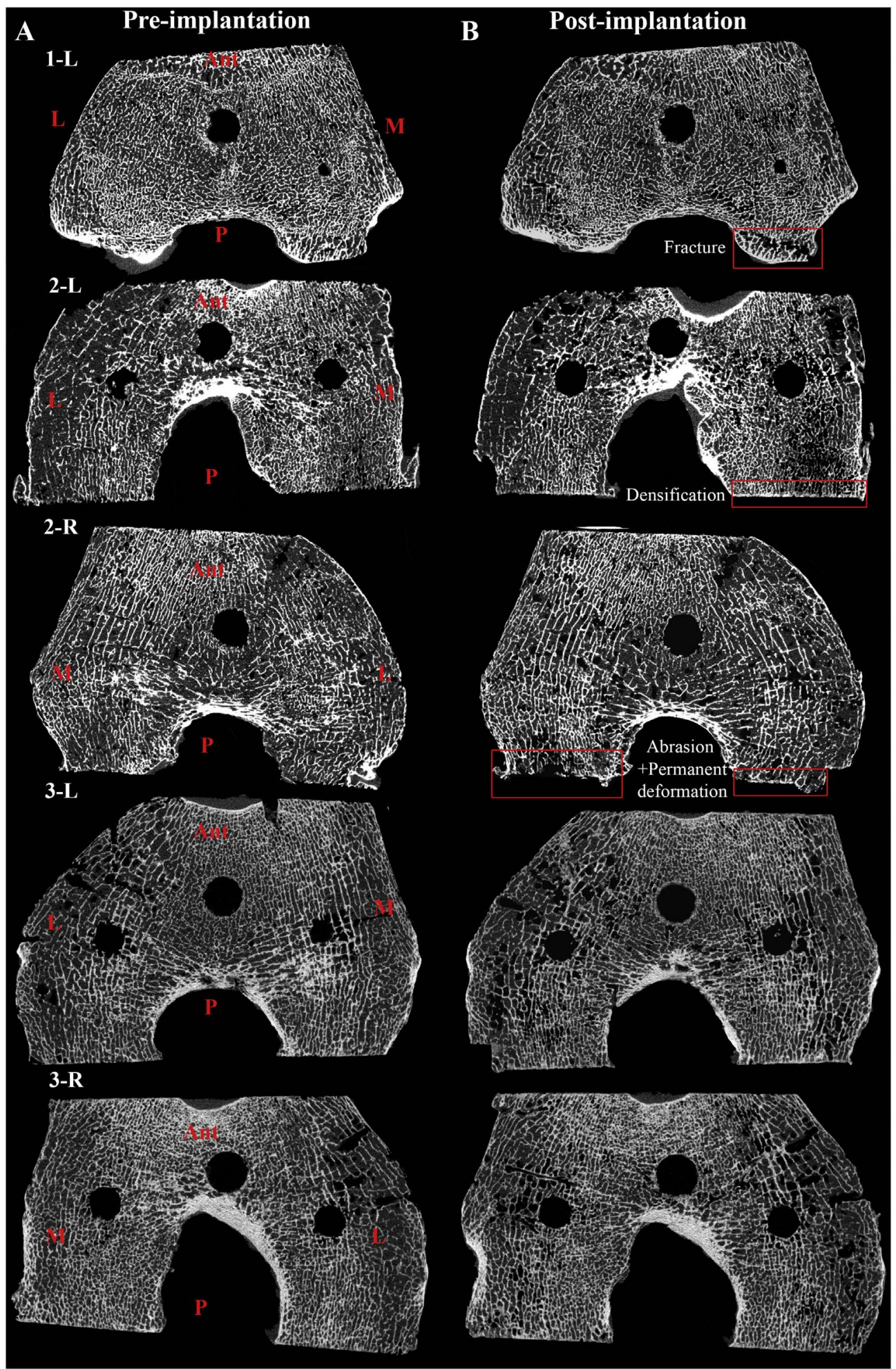

Fig. 7. Two slices from (A) pre- and (B) postimplantation micro-CT scan of each specimen are shown to illustrate different phenomena that occurred during implantation. Slices are selected from the same distance from the most distal slide. Medial, lateral, anterior and posterior regions are indicated by $\mathrm{M}, \mathrm{L}$, ant, and $\mathrm{P}$, respectively. randomly in both anterior and posterior regions (Fig. 3A). By comparing all ROIs, the PL region of specimen B-Right had the maximum deviation from the nominal cutting planes (under-resection) with mean $0.72 \mathrm{~mm}$ (SD $0.25 \mathrm{~mm}$ ) was found in. The largest average deviation in the AP direction was found in specimen 2-Left $(0.85 \mathrm{~mm}$ (SD $0.24 \mathrm{~mm})$ ). No correlation was found between BMD and cutting error (Fig. 4A).

\subsection{Actual interference fit}

A more homogenous distribution of the actual interference fit in the posterior and anterior regions was found in comparison to the cutting error, which can be seen from both the frequency graphs with the three lines overlaying each other and the distribution maps, with a more homogenous colour in the three ROIs (Fig. 3B). The highest interference fit in the AP-direction was found for specimen C-Right (mean $1.69 \mathrm{~mm}$ (SD $0.36 \mathrm{~mm}$ )). 
Table 2

Recorded strain of four strain gauges and their average per location and per specimen are given.

\begin{tabular}{|c|c|c|c|c|c|}
\hline \multirow[t]{2}{*}{ Specimen } & \multicolumn{4}{|c|}{ Strain per location $(\mu \varepsilon)$} & \multirow{2}{*}{$\begin{array}{l}\text { Average } \\
\text { strain (SD) } \\
(\mu \varepsilon)\end{array}$} \\
\hline & AL & PL & $\mathrm{AM}$ & PM & \\
\hline 1-Left & 481 & 703 & 447 & - & $\begin{array}{l}543.67 \\
(139.03)\end{array}$ \\
\hline 2-Left & - & 507 & 329 & 261 & $\begin{array}{l}365.67 \\
(127.03)\end{array}$ \\
\hline 2-Right & 269 & 445 & 378 & 50 & $\begin{array}{l}285.5 \\
(172.94)\end{array}$ \\
\hline 3-Left & 855 & - & 1842 & 906 & $\begin{array}{l}1201.00 \\
(555.70)\end{array}$ \\
\hline 3-Right & 1172 & 2078 & 864 & 812 & $\begin{array}{l}1231.50 \\
(586.27)\end{array}$ \\
\hline Average (SD) & $\begin{array}{l}694.25 \\
(400.17)\end{array}$ & $\begin{array}{l}933.25 \\
(771.05)\end{array}$ & $\begin{array}{l}772.00 \\
(634.52)\end{array}$ & $\begin{array}{l}507.25 \\
(416.97)\end{array}$ & \\
\hline
\end{tabular}

\subsection{Bone damage assessment}

\subsubsection{Outer surface}

Generally, damage in the anterior region was less evident by visual inspection of the bone specimens, and it seemed that the bone surface was polished (Fig. 5A), however, bone was clearly deformed and crushed in the posterior region (Fig. 5B). At the medial and lateral condyles per specimen a similar pattern of damage was observed, which can be seen clearly in the frequency graphs (Fig. 6A). However, the interspecimen comparison showed noticeable differences between specimens, with higher damage associated with lower bone density $\left(\mathrm{R}^{2}=0.94 ; P=0.006\right.$ ) (Fig. 4B). In one case (specimen 2-Right), bone was even pushed outwards (extruded) in the distal region of the condyles (Fig. 6A (2-R)). This specimen also had the largest nodal damage in the proximal region of condyles $(1.75$ and $1.70 \mathrm{~mm}$ laterally and medially, respectively).

\subsubsection{Internal}

Several visible phenomena occurred in the post-implantation microCT. In one case, a deep fracture was seen in the superior region of the lateral condyle (specimen A). In addition, depending on the location in the anterior and posterior regions, bone densifications in the form of a thin layer of a white line at the interface (specimen 2-Left in Fig. 7) and/or clear bone abrasion were seen, probably accompanied by permanent deformation of the bone (specimen 2-Right in Fig. 7).

\subsection{Effective interference fit}

A large elastic deformation in the specimens of good bone quality was found with mean $1.12 \mathrm{~mm}$ (SD $0.18 \mathrm{~mm}$ ) and $1.38 \mathrm{~mm}$ (SD $0.32 \mathrm{~mm}$ ) in specimen 3-L and 3-R, respectively (Fig. 6B). Other specimens had a smaller effective interference fit and the correlation with
BMD was statically significant $\left(\mathrm{R}^{2}=0.94 ; P=0.006\right)$ (Fig. 4C).

\subsection{Implant deformation}

Three strain gauges, which belonged to three different specimens, were lost during implantation. No clear inter-specimen trend was found in terms of strain gauge location, but generally the largest strain (mean $933.25 \mu \varepsilon$ (SD $771.05 \mu \varepsilon$ )) was recorded in the PL strain gauge (Table 2). In addition, the correlation between BMD and strain showed a significant strong correlation $(P=0.007)$ (Fig. 4D).

\section{Discussion}

The current study focused on the evaluation of interference fit and bone damage occurring during implantation of femoral knee implant using image analysis techniques; because both are affected by cutting errors and bone density, we included these parameters in our investigation as well.

To our knowledge, this is the first study investigating bone damage that occurs during implantation of a femoral knee component using micro-CT, which enabled us to demonstrate different phenomena that can happen to trabeculae in a press-fit situation underneath the femoral component. It was out of our scope to perform quantitative analysis of micro-CT scans, but our observations indicated that bone can be damaged beyond its interface with the implant. In addition, bone particles can penetrate into the inter-trabecular spaces, which can be considered as a negative observation for initial fixation, but on the longer term these particles may stimulate bone ingrowth (Tabassum et al., 2011). According to our expectation, different phenomena occurred to the bone specimens during implantation: bone was deformed both permanently (inelastic) and reversibly (elastic) (Fig. 7). In addition, abrasion occurred creating bone particles in three locations: $1-$ at the surface coating of implant (Fig. 8A and B), 2 - within the porosity of bone, seen as a white line at the interface of the post-implantation micro-CT scans (Fig. 7, specimen 2-Left), 3 - and bone particles being scraped out, which was evident only in the low bone density specimens (Fig. 8C). However, the degree of each of these phenomena was largely dependent on the bone quality. Bishop et al. (2014) measured the pressfit bone damage using blocks of bone and titanium plates with different surface coatings, and one of these (beaded) having very similar properties to the surface coating of the implant in our study. Similar to our results, they found a combination of plastic deformation and abrasion, which was quantified mainly as abrasive when using a rough surface coating. More recently Damm et al. (2017) also demonstrated the local bone densification due to implantation.

The amount of interference fit designed into the system by the manufacturer was $0.75 \mathrm{~mm}$ in the anterior and posterior regions, resulting in $1.5 \mathrm{~mm}$ of AP interference fit in total. Similarly, we found an average actual interference fit of $1.48 \mathrm{~mm}(\mathrm{SD} 0.27 \mathrm{~mm})$ for all specimens. However, the actual interference fit was not distributed

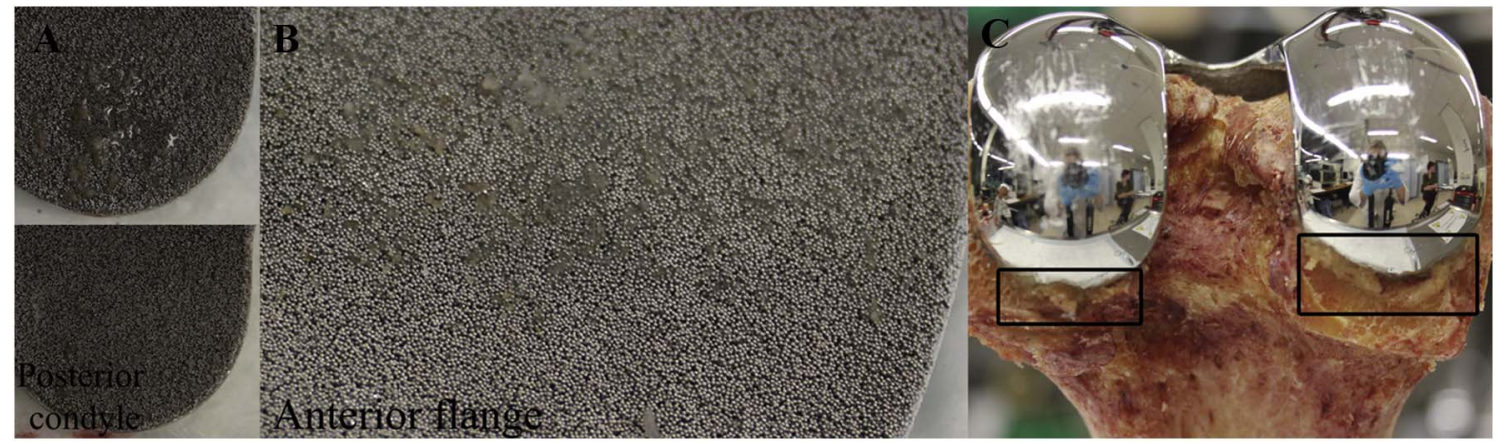

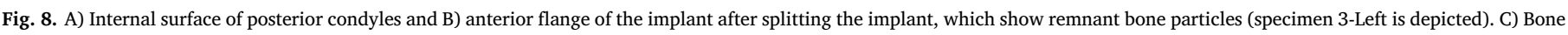
particles were scraped out after implantation (specimen 3-Left) which can be seen as a layer around the interface of the posterior condyles (inside the boxes). 
homogenously, between posterior and anterior regions and also per ROI, due to combination of cutting errors and imperfect implant seating. The work of Otani et al. (1993) is one of the few investigations into the range of the cutting error, and the sources of this error. They reported a range of cutting error between 100 and $1000 \mu \mathrm{m}$ dependent on the type of saw blade and the use of a fixed cutting guide. In addition, they showed a higher deviation from nominal cuts in the more proximal region of both anterior and posterior cut planes. Our measured range was similar to that study and also in the current study the same increasing trend towards the proximal region was observed in most of the cases. Hence, the cutting error might be due to toggling/ bending of the saw blade and displacement of the cutting guide, as shown by Otani et al. (1993). In addition, thirteen out of the fifteen ROIs currently analyzed were under-resected (less bone removed than planned), which means in most regions the primary fixation was not jeopardized by introducing a gap between bone and implant. No trend was seen between cut accuracy and BMD, which is consistent with our previous study (Berahmani et al., 2015). This suggests that other factors such as surgical technique and surgeon experience may be more important.

The actual and effective interference fits that were determined in the current study may actually have been affected by deformation of the implant (which was assumed to be completely rigid during calculation procedure), as indicated by the strain measurements with the femoral components. To quantify the amount of implant opening, and thus its effect on the interference fit, we performed a simple finite element simulation in which the posterior condyles were fixed, while applying an external load to the anterior flange. Our analysis showed that an average opening of 100 to $500 \mu \mathrm{m}$ in the AP direction would result to the same range of strain as found in the experiment. Consequently, the average elastic deformation would be mean $820 \mu \mathrm{m}$ (SD $480 \mu \mathrm{m})$ minus the computed range of implant opening, which would result in a range of effective interference fit between $30 \mu \mathrm{m}$ and $880 \mu \mathrm{m}$. Damm et al. (Damm et al., 2017) also found a wide range of effective interference fit between 30 and $80 \%$ of nominal interference fit mainly depends on the nominal interference fit. Damm et al. (2017) showed that there is a relationship between the amount of bone deformation and the fixation strength, which highlights the necessity to evaluate bone deformation to capture the entire bone-implant behaviour.

Burgers et al. (2010) performed similar strain gauge measurements which showed a range of strain close to our worst bone quality. In our previous study (Berahmani et al., 2015), we also found a wide range of strain dependent on the bone density, which had a maximum of $700 \mu \varepsilon$ for the best bone quality. The current results are similar to the previous findings, although the peak strains were somewhat larger. Since the BMD values were in the same range for both studies, this could be due to the difference in implant size and non-uniform scaling between sizes.

The implant studied here, the cruciate retaining cementless Sigma ${ }^{\circledR}$ PFC (DePuy Synthes Joint Reconstruction, Leeds, UK), is one of the most commonly used TKR implant designs (Sundberg et al., 2016), with a 10-year survival rate of $94.4 \%$ (Graves and Turner, 2016). As such, with regards to the methodology presented here, this implant design can serve as a benchmark of a clinically well-performing implant, and can be used as a predicate device when evaluating other implant designs, coatings, or other implant features.

\subsection{Limitations}

We have tested only one type of implant, performed the implantation by one surgeon, and had a limited sample size. However, we believe that the current study provides a detailed insight into the bone damage and interference fit of cementless femoral knee implants. Due to providing fixation of implant mainly by clamping power of AP-interference fit, measurements were only in the anterior and posterior regions. Though, it is possible that a more complete analysis of the fully resected bone may provide a deeper understanding of implantation procedure. Our observation, however, showed that the complete contact in the distal surface and chamfers was not achieved in all cases. Therefore, we believe that bone damage and interference fit would be minimal in these regions and would not affect our results.

\subsection{Conclusion}

This study indicated that several factors are involved in the press-fit implantation of uncemented femoral knee implants. We found a complex interaction between cutting error, implant positioning, and bone density. It was demonstrated that on average the nominal interference fit was achieved, but it was not a homogenous distribution over all surfaces. In addition, bone damage and effective interference fit are dependent on the bone density, which emphasizes the significance of good bone quality selection for the cementless implantation. Finally, the interference fit determined in the current study can be used in computational analyses to evaluate primary fixation of femoral components, and can be used to fine-tune the design process when developing cementless femoral TKR components.

\section{Conflict of interest statement}

The authors would like to disclose that this work was supported by a research grant from DePuy Synthes Joint Reconstruction (Leeds, UK). Authors have no conflict of interest to disclose.

\section{Acknowledgments}

This work was supported by a research grant from DePuy Synthes Joint Reconstruction (Leeds, UK). The authors would like to thank orthopaedic surgeon, Dr. S. van de Groes, for performing implantation and Mr. F. Baan for his help with the optical scanning.

\section{References}

Abdul-Kadir, M.R., Hansen, U., Klabunde, R., Lucas, D., Amis, A., 2008. Finite element modelling of primary hip stem stability: the effect of interference fit. J. Biomech. 41 (3), 587-594 (Epub 2007/11/27).

Aro, H.T., Alm, J.J., Moritz, N., Makinen, T.J., Lankinen, P., 2012. Low BMD affects initial stability and delays stem osseointegration in cementless total hip arthroplasty in women: a 2-year RSA study of 39 patients. Acta Orthop. 83 (2), 107-114 (Epub 2012/04/12).

Berahmani S, Janssen D, Wolfson D, Rivard K, de Waal Malefijt M, Verdonschot N. The effect of surface morphology on the primary fixation strength of uncemented femoral knee prosthesis: a cadaveric study. J. Arthroplast. 2015;30(2):300-7. (Epub 2014/ 12/03).

Berahmani, S., Janssen, D., Wolfson, D., de Waal Malefijt, M., Fitzpatrick, C.K., Rullkoetter, P.J., et al., 2016. FE analysis of the effects of simplifications in experimental testing on micromotions of uncemented femoral knee implants. J. Orthop. Res. 34 (5), 812-819.

Bishop, N.E., Hohn, J.C., Rothstock, S., Damm, N.B., Morlock, M.M., 2014. The influence of bone damage on press-fit mechanics. J. Biomech. 47 (6), 1472-1478 (Epub 2014/ 02/08).

Burgers, T., Mason, J., Squire, M., Ploeg, H.L., 2010. Time-dependent fixation and implantation forces for a femoral knee component-an in vitro study. Med. Eng. Phys. 32 (9), 968-973.

Damm, N.B., Morlock, M.M., Bishop, N.E., 2015. Friction coefficient and effective interference at the implant-bone interface. J. Biomech. 48 (12), 3517-3521 (Epub 2015/ 08/01).

Damm, N.B., Morlock, M.M., Bishop, N.E., 2017. The influence of trabecular bone quality and implantation direction on press-fit mechanics. J. Orthop. Res. http://dx.doi.org/ 10.1002/jor.23257. (1554-527X (Electronic)).

Graves, S., Turner, C., 2016. National Joint Replacement Registry — Annual Report 2016. Australian Orthopaedic Association National Joint Replacement Registry, Adelaide, Australia.

Hadi, M., Barlow, T., Ahmed, I., Dunbar, M., McCulloch, P., Griffin, D., 2015. Does malalignment affect revision rate in total knee replacements: a systematic review of the literature. SpringerPlus 4, 835 (Epub 2016/01/12).

Hungerford, D.S., 1991. The technique of cementless total knee replacement. Tech. Orthop. 6 (4), 1-7.

Jasty, M., Bragdon, C., Burke, D., O'Connor, D., Lowenstein, J., Harris, W.H., 1997. In vivo skeletal responses to porous-surfaced implants subjected to small induced motions. J. Bone Joint Surg. Am. 79 (5), 707-714 (Epub 1997/05/01).

Kienapfel, H., Sprey, C., Wilke, A., Griss, P., 1999. Implant fixation by bone ingrowth. J. Arthroplast. 14 (3), 355-368 (Epub 1999/04/29). 
Lennox, D.W., Cohn, B.T., Eschenroeder Jr., H.C., 1988. The effects of inaccurate bone cuts on femoral component position in total knee arthroplasty. Orthopedics 11 (2), 257-260 (Epub 1988/02/01).

Otani, T., Whiteside, L.A., White, S.E., 1993. Cutting errors in preparation of femoral components in total knee arthroplasty. J. Arthroplast. 8 (5), 503-510.

Pilliar, R.M., Lee, J.M., Maniatopoulos, C., 1986. Observations on the effect of movement on bone ingrowth into porous-surfaced implants. Clin. Orthop. Relat. Res. 208, 108-113 (Epub 1986/07/01).

Sundberg, M., Lidgren, L., W-Dahl, A., Robertsson, O., 2016. Swedish Knee Arthroplasty
Register - Annual Report 2016. Lund University, Lund, Sweden.

Tabassum, A., Walboomers, F., Wolke, J.G., Meijer, G.J., Jansen, J.A., 2011. The influence of surface roughness on the displacement of osteogenic bone particles during placement of titanium screw-type implants. Clin. Implant. Dent. Relat. Res. 13 (4) 269-278 (Epub 2009/08/14).

Taylor, M., Barrett, D.S., Deffenbaugh, D., 2012. Influence of loading and activity on the primary stability of cementless tibial trays. J. Orthop. Res. 30 (9), 1362-1368 (Epub 2012/01/24). 